\title{
Peningkatan Penguatan Pendidikan Karakter Siswa Melalui Pemberdayaan Kompetensi Sosial dan Kepribadian Guru
}

\author{
Harlinda Syofyan ${ }^{1 *}$, Ratnawati Susanto ${ }^{2}$, Ritta Setiyati ${ }^{3}$, Vebryanti ${ }^{4}$, Dita \\ Ramadhanti $^{5}$, Indah Mentari ${ }^{6}$, Ratih ${ }^{7}$, Karina Dwiyanti ${ }^{8}$, Heni Oktavia ${ }^{9}$, Melinda \\ Tesaniloka $^{10}$ iD \\ 1,2,3,4,5,6,7,8,9,10 Universitas Esa Unggul, Indonesia \\ *Corresponding author: syofyan00@ gmail.com
}

\begin{abstract}
Pendidikan karakter diselenggarakan untuk mengarahkan institusi Pendidikan dalam pencapaian pembentukan karakter dan akhlak mulia siswa secara terpadu, utuh, dan seimbang dan tergambar dalam perilaku sehari-hari. Guru sebagai sosok yang selalu diteladani segala tindakan dan tingkah lakunya oleh siswanya mesti selalu menjaga sikap, memberikan hal-hal yang baik kepada semua siswanya. PKM penguatan Pendidikan karakter siswa ini diadakan di SDN Grogol 05 Pagi, yang bertujuan untuk memberikan penyegaran kepada guru-guru dalam kompetensi sosial dan kepribadannya untuk dapat diarahkan dalam penguatan karakter siswanya. Hal ini diungkapkan dari hasil wawancara dengan kepala sekolah mitra, untuk memberikan penyegaran kembali kepada guru-guru untuk lebih menonjolkan kompetensi kepribadian dan sosial . Hasil supervisi dan dari pengamatan kepala sekolah ini menjadi acuan dan permintaan kepada tim PKM untuk diberikan pelatihan dan penyegaran agar, kompetensi menjadi lebih baik dan dapat ditularkan ke siswanya melalui keteladanan. PKM ini dilakukan dengan kegiatan sosialisasi, pelatihan, implementasi dalam pembelajaran dan pengukuran melalui observasi dan penyebaran kuesioner. Hasil PKM menunjukkan adanya peningkatan kompetensi sisial $* \%$ dan kepribadian guru $7 \%$, dan pada penguatan butir karakter dari siswa juga terjadi peningkatan
\end{abstract}

Keywords: Penguatan, Pendidikan karakter, Pemberdayaan, Kompetensi

\section{Abstract}

Character education is held to direct educational institutions in achieving the formation of character and noble character of students in an integrated, comprehensive, and balanced manner and is reflected in daily behaviour. The teacher as a figure who is always imitated by all his actions and behaviour by his students must always maintain an attitude, provide good things to all his students. This was revealed from the results of interviews with partner school principals, to provide refreshment for teachers to further highlight personal and social competencies. The results of the supervision and from the observations of the school principal become a reference and request for the PKM team to be given training and refresher so that competence becomes better and can be transmitted to students through exemplary. PKM for strengthening student character education is held at SDN Grogol 05 Pagi, which aims to provide refreshment for teachers in their social and personal competencies to be directed towards strengthening the character of their students. This PKM is carried out by socialization, training, implementation in learning, and measurement through observation and questionnaires. The PKM results show an increase in the social competence of $8 \%$ and the teacher's personality of $7 \%$, and in strengthening the character items of students there is also an increase.

Keywords: Strengthening, character education, empowerment, competence

\section{Introduction}

Segala tindakannya dalam pembelajaran di sekolah merupakan tanggung jawab Guru. Dalam bermasyarakat Guru merupakan pendidik, yang menjadi tokoh, panutan, dan

$\begin{array}{lll}\text { History: } & & \text { Publisher: Undiksha Press } \\ \text { Received } & \text { : 02 August } 2020 & \text { Licensed: This work is licensed under } \\ \text { Revised } & : 09 \text { September } 2020 & \text { a Creative Commons Attribution 3.0 License } \\ \text { Accepted } & : 06 \text { October } 2020 & \\ \text { Published } & : 30 \text { November } 2020 & \end{array}$


identifikasi bagi siswa, dan lingkungannya (Huda, 2018; Prihartini et al., 2019). Sehingga guru harus memiliki standar kualitas pribadi tertentu yang sudah, yang mencakup tanggung jawab, wibawa, mandiri, dan disiplin. Tanggung jawab guru berkaitan untuk mengetahui, serta memahami nilai, norma moral, dan sosial, serta berusaha berprilaku dan berbuat sesuai dengan nilai dan norma tersebut. Berkenaan dengan wibawa, guru harus memiliki kelebihan dalam merealisasikan nilai spiritual, emosional, moral, sosial, dan intelektual dalam pribadinya, serta memiliki kelebihan dalam pemahaman ilmu pengetahuan, teknologi, dan sesuai dengan bidang yang dikembangkan (Syofyan, Harlinda; Rosyid, 2020);(Putri \& Syofyan, 2018). Siswa dibantu oleh guru dalam mengembangkan pengetahuannya agar mampu membentuk komoetenssi tertentu. Untuk itu guru juga disebut sebagai model atau teladan bagi siswa. Perlu dipahami juga bahwa peran dan fungsi ini patut dipahami, dan tidak perlu menjadi beban yang memberatkan, sehingga dengan keterampilan dan kerendahan hati akan memperkaya arti pembelajaran. Siswa dan orang ada disekitar seorang guru, akan mengganggap perbuatannya adalah panutan dan segala tindakannya selalu menjadi sorotan. Dan kompetensi ini harus dijaga terus oleh seorang guru professional. Hal ini tergambar dalam kompetensi yang harus dimiliki oleh seorang guru. Karena profesi seorang guru merupakan paket komplit dari empat kompetensi yakni professional, pedagogik, sosial, dan kepribadian (Sudrajat, 2011).

Karakter merupakan tabiat, bawaan karena suatu kebiasaan yang telah dilakukan berulang-ulang. Pendidikan karakter merupakan pendidikan nilai atau pendidikan budi pekaerti dalam berinteraksi dengan orang lain. Hal ini harus dihidupkan dan dicontohkan oleh guru di sekolah kepada siswanya. Karna proses pembinaan karakter ini akan mengarahkan siswa dalam peningkatan kualitas pendidikan dan kepribadian yang harmoni dengan sesama dalam lingkungannya dalam menebar kebaikan dalam hidup sehari-hari dengan hati penuh dan karakter baik (good character) yang diusung oleh Kehidupan yang penuh kebajikan (the virtuous life) sendiri oleh (Khusniati, 2012), dibagi dalam dua kategori, yakni kebajikan terhadap diri sendiri (selforiented virtuous) seperti pengendalian diri (self-control) dan kesabaran (moderation); dan kebajikan terhadap orang lain (other-oriented virtuous), seperti kesediaan berbagi (generousity) dan merasakan kebaikan (compassion); (Syofyan.Harlinda, 2019). Perlunya dilakukan penguatan karakter yang perlu didukung oleh semua warga sekolah, karena degradasi moral yang makin hari makin mencuat, kekerasan dan bullying, ujaran kebencian, makian, dan terlalu ingin tahu urusan orang lain serta berbagai tingkah laku lainnya yang menjadi pemcu keboborakan moral yang semakin tidak terkendali (Komara, 2018). Hal ini bisa diperbaiki melalui institusi Pendidikan yang merupakan garda terdepan bagi siswa untuk menuntut ilmu dan berprilaku. Harapan memperbaiki ini semua tentu saja harus membekali guru-guru di sekolah dengan kompetensi yang kuat. Hasil wawancara dari kepala sekolah dari kunjungan observasi yang dilakukan, ada beberapa hal yang menjadi konsentrasi perbaikan oleh mitra. Pihak manajemen sekolah mitra sangat membutuhkan pendampingan dan kerjasama dari pihak eskternal untuk pendampingan dan pelatihan baik bagi kepala sekolah mencakup manajemen sekolah, kepemimpinan, supervisi, mentoring, coaching, program pelatihan dan pengembangan guru dan kompetensinya dan tata usaha, pengembangan program kesiswaan secara akademik dan ekstrakurikuler. Dari gambaran permasalahan yang ada, maka potensi/peluang pemberdayaan mitra SDN Grogol 05 Pagi yang dapat dilakukan adalah memfasilitasi Sekolah mitra untuk menjadi organisasi pembelajar dengan warga sekolah yang selalu mau belajar, bertumbuh dan berkembang melalui pemberdayaan guru dalam memenuhi tugas dan tanggung jawabnya dalam berbagai aspek yang memungkinkan semua warga sekolah mampu Learn to know, learn to do, learn to be, learn how to live together dan learn how to see.

Pada kegiatan PKM ini yang disoroti adalah kompetensi sosial dan kepribadian guru sebagai modal pemberdayaan untuk menguatkan karakter siswa. Sehingga disepakati untuk 
memperbaiki kompetensi sosial dan kepribadian dengan melakukan penyegaran karena kegiatan sosialisasi indan penyegaran jarang dilakukan. Hal ini sejalan dengan penilitian terdahulu yang menyatakan bahwa, tindak tanduk selalu guru mesti dijaga keberadaannya yakni berupa sikap dasar, gaya bicara, kebiasaan bekerja, sikap melalui pengalaman dan kesalahan, cara berpakaian, hubungan kemanusiaan, cara berpikir, perilaku, gaya hidup, serta pengambilan keputusan. Hal tersebut akan jadi panutan yang akan ditiru oleh siswanya. Siswa sebagai bagian dari satuan Pendidikan tempat dimana mereka menuntut ilmu, memiliki tanggung jawab untuk mengembangkan sikap, pengetahuan, dan sejumlah keterampilan lainnya. Artinya siswa yang dibentuk harus terdidik (educated) dan memiiliki peradaban (civilized) (Marzuki, 2012).

Hal ini sejalan dengan penelitian (Wulandari \& Andhiarini, 2018), bahwa pemberdayaan guru dalam penguatan Pendidikan karakter penting dilakukan dengan sosialisasi, mengundang pemateri untuk memberikan pelatihan, kenudian diberikan pendampingan dalam berbagai kegiatan, dengan contoh-contoh penerapannya dalam kegidupan sehari-hari. Peneltian ini juga didukung oleh penelitan lainnya yang menyatakan bahwa sebelum melakukan pengajaaan yang bersentuhan dengan generasi penerus bangsa mesti diberikan kompetensi sosial dan kepribadian yang kuat agar meberikan suri tauladan bagi siswanya. Itulah bagian penting dari peran pendidik dalam pembentukan karakter siswanya (Megawati \& Kawatu, 2019);Islam, 2017). Program Pendidikan karakter yang dicanangkan pemerintah belum sepenuhnya terlaksana sampai saat ini. Walaupun telah dihimbau untuk melakukan internalisasi Pendidikan karakter ini di dalam setiap mata pelajaran, dan juga belum ditemukannya guru yang memiliki keterampilan tinggi dalam melaksanakan proses pembelajaran yang mengintegraasikan nilai-nilai karakter ke dalam mata pelajaran yang diajarkan. Hal ini juga yang menjadi motivasi dilaksanakan kegiatan PKM ini untuk penguatan Pendidikan karakter siswa dilakukan melalui pemberdayaan kompetensi guru yakni kompetensi sosial dan kepribadiannya.

\section{Materials and Methods}

Program Kemitraan Masyarakat (PKM) ini dilaksanakan di SDN Grogol 05 Pagi Jakarta Barat. Metode kegiatan yakni dengan partisipatif dengan aktifnya guru dalam kegiatan, Untuk tetap telaksananya kegiatan PKM ini yang sedang dalam masa pandemi, dan beradaptasi dengan Pembatasan Sosial Berskala Besar (PSBB), dan untuk mematuhi protokol kesehatan yang berlaku pada masa kegiatan, maka kegiatan PKM ini dilaksanakan secara virtual dalam sosialisasi kegiatan, dan kepentingan pengambilan data membagikan kuesioner dengan google form, serta pengamatan dan observasi juga lebih banyak secara online dilakukan. Pelaksanaan kegiatan yang dilakukan terdi dari tahap (1) Sosialisasi tentang kompetensi sosial dan kepribadian guru, (2) Refleksi dalam pembelajaran, (3) Pengembangan karakter dalam RPP, (4) Evaluasi kegiatan yang dapat dilihat dalam Gambar 1 berikut. 


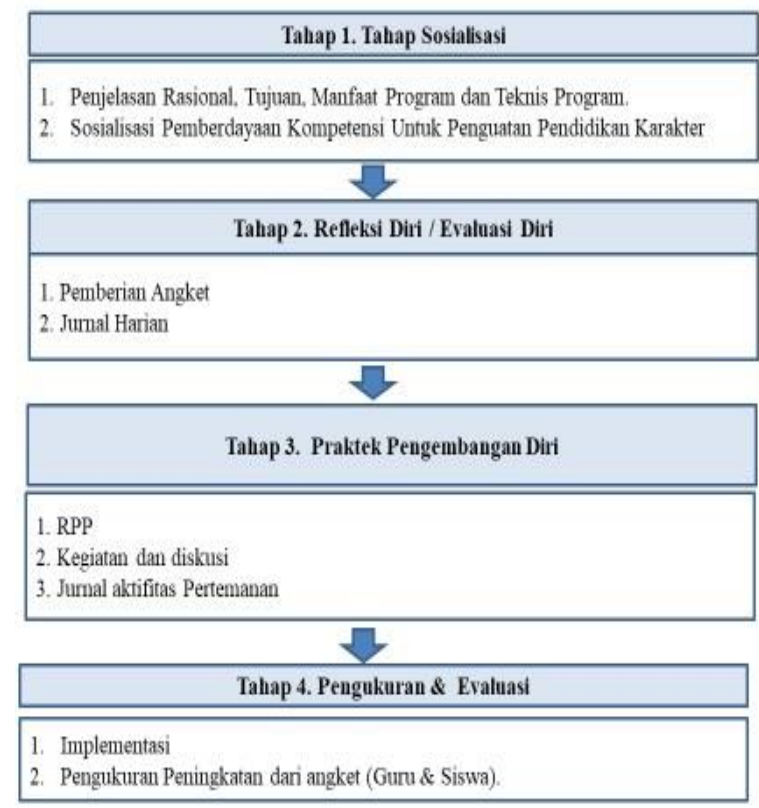

Gambar 1. Tahapan Kegiatan Program Kemitraan Masyarakat

\section{Results and Discussion}

Hasil kegiatan PKM yang berlangsung dari Mei sampai Oktober 2020, akan dijelaskan dalam uraian berikut ini.

\section{Tingkat Partisipasi Sekolah Mitra}

Partisipasi guru sebagai sekolah mitra dalam pelaksanaan PKM ini sangat diharapkan untuk kesuksesan PKM, dan juga untuk terlaksananya penguatan karakter bagi siswa, dengan memberdayakan kompetensi sosial dan kepribadian guru. Secara umum tim mitra menerima kegiatan yang dilaksanakan, namun karena keterbatasan waktu dan tugas yang cukup berat dengan berabagai perubahan pelaksanaan pembelajaran, guru sibuk dengan adaptasi dengan cara-cara baru, sehingga tim PKM agak susah mengatur waktu yang tepat untuk pelaksanaannya. Namun akhirnya kegiatan ini tetap terlaksana dengan cukup baik. Walaupun ada beberapa kendala yang kami hadapi baik dari segi teknis dan kesibukan dari tim mitra.

Partisipasi Kontribusi Mitra pada pelaksanaan PKM ini dapat dikatakan cukup mendukung, karena situasi dan dipengaruh oleh pembelajaran dilakukan di masa pandemi, pekerjaan tim mitra makin bertambah sejak diadakannya pembelajaran serba online. Tingkat keaktifan peserta dalam kegiatan peserta PKM diukur dengan tingkat kehadiran peserta di sekolah mitra adalah: 6 peserta (54\%) di SDN Grogol 05 Pagi, sebagai keterlibatan aktif dari keseluruhan program, hal ini dikarenakan berbagai kemungkinan, karena dilakukan dengan virtual/online, ada yang menginformasikan, susah mengakses link zoom yang diberikan, dan juga kemungkinan adanya gangguan jaringan dan fitur telepon genggam yang kurang baik, serta ada sebagian guru pada saat itu sedang menyelesaikan penilaian untuk akhir semester yang harus mereka selesaikan. Namun demikian, bahan materi yang disampaikan tetap dikirinkan ke mitra PKM agar mereka tetap mengakses materi yang diberikan.

\section{Profil Kompetensi Sosial dan Kepribadian}

Profil Guru dilihat dari Kompetensi Sosial dan Kepribadiannya, dapat diketahui dengan memberikan beberapa pertanyaan yang berhubungan dengan kompetensi sosial dan kepribadian yang menjadi dasar dari program kemitraan masyarakat ini. Instrumen kuesioner kompetesi ini difokuskan pada aspek kompetensi sosial yang mencakup; kepedulian, 
komunikasi, dan sikap serta hubungan yang baik terhadap Siswa, rekan kerja dan atasan, sedangkan aspek kompetensi kepribadian meliputi, ketaatan, tingkah laku, baik dalam penampilan, serta keterbukaan dalam bersikap. Dari pengembangan instrument tersebut, maka setelah merinci hasil kuesioner dari kompetensi guru tersebut pada kompetensi sosial dan kepribadian, didapatkan hasil pada gambar 2 berikut.

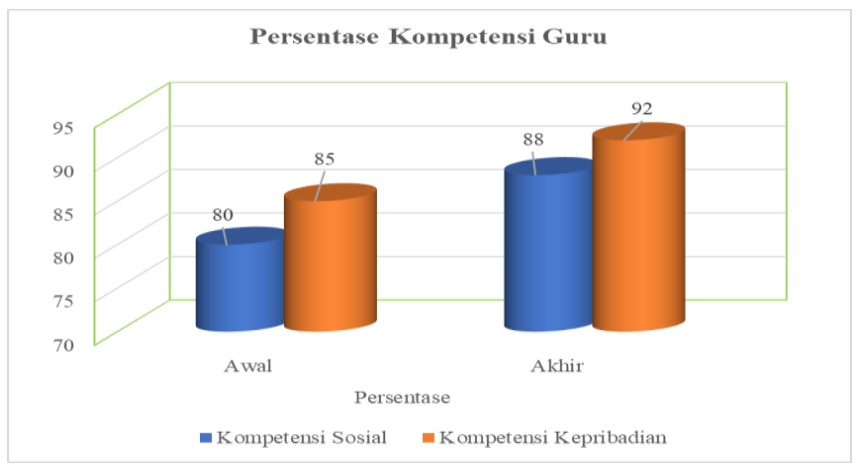

\section{Gambar 2. Persentase Kompetensi Sosial \& Kepribadian}

Dari gambar 2 di atas dapat dilihat ada kenaikan dari masing-masing kompetensi yang diukur, masing-masing aspek mengalami kenaikan, yaitu 8\% pada kompetensi sosial dan 7\% pada kompetensi kepribadian. Hal ini menunjukkan bahwa guru sudah memiliki kompetensi yang baik dalam diri mereka sejak menjalankan profesi mereka sebagai guru. Karena dengan pengalaman lamanya mereka Hasil pengolahan data kuesioner ada beberapa aspek dari dari guru yang mengajar dengan lama 1-5 tahun, ada beberapa aspek kompetensi sosial dan kepribadian yang masih dalam kategori cukup dilakukan, dimana aspek ini harus ditingkatkan pada saat mendatang dalam upaya untuk dijadikan contoh dalam menguatkan karakter siswa. Guru dengan pengalaman mengajar diatas 15 tahun, dalam beberapa aspek kompetensi sosial dan kepribadian, dalam penerapannya juga masih dikategorikan cukup, hal ini kemungkinan disebabkan karena kurangnya penyegaran dari kompetensi guru yang dilakukan, sehingga kebiasaan yang harus dijadikan contoh oleh siswa, terkadang bisa kandas karena kesibukan atau hal lain. Hal ini juga didukung oleh penelitian (Susanto et al., 2020), bahwa harus menjadi perhatian kita semua, agar kompetensi guru harus dilatih secara terus menerus baik dalam sekolah sendiri ataupun mengikuti pelatihan yang dilakukan oleh suku dinas terkait secara berkala. Kemudian dilakukan pengukuran agar dapat diketahi perkembangan dan rencana perbaikan yang harus dilakukan pada kesempatan berikutnya.

Hal ini dikuatkan oleh penelitian (Supadi et al., 2020), bahwa perlu dilakukan pengukuran dan pemantauan dalam kompetensi guru agar kualitas pengajaran tetap terjaga dengan memberikan pelatihan ataupun pembiasaan. Kemudian dari penelitan (Oviyanti, 2017 ;Susanto et al., 2020) yang megupas tentang hubungan interpersonal yang mengarah kepada kompetensi sosial da kepribadian yang sering terabaikan karena tuntutan kompetensi professional dan pedagogik. Dimana dalam artikelnya juga diungkapkan bahwa kecerdasan interpersonal berupa sikap empati, kesadaran diri, pro sosial, kemampuan berkomunikasi dan beradaptasi sangat dioerlukan dalam menjalankan tugas luhurnya sebagai seorang guru. Hal ini perlu dilatihkan dan dikuatkan secara terus menerus agar berimbas kepada siswa yang dididiknya tiap hari di kelas. Karena tanpa dasar karakter yang baik serta tauladan yang minim, maka sulit untuk direalisasikan (Zakaria et al., 2020); (Shah \& Coles, 2020). 


\section{Profil Penguatan Karakter Siswa}

Mengembangkan kemampuan dan membentuk watak serta peradaban bangsa yang bermartabat dalam rangka mencerdaskan kehidupan bangsa merupakan maksud dari Pendidikan karakter. Pendidikan karakter dimaksudkan untuk. Profil karakter siswa yang diamati dalam PKM ini adalah (a) Pendidikan karakter yang mengembangkan potensi dasar siswa agar berhati baik, berpikiran baik, dan berprilaku baik, (b) memperkuat dan membangun perilaku bangsa yang multikultur, dan (c) meningkatkan peradaban bangsa yang kompetitif dalam pergaulan dunia. Melalui berbagai media yang mencakup keluarga, satuan Pendidikan, masyarakat sipil, masyarakat politik, pemerintah, dunia usaha, dan meda massa Pendidikan karakter bisa dilakukan (Winangun, 2020).

Pakar Pendidikan mengusulkan 18 karakter yang haris diinternalisasikan dalam pembelajaran yaitu; (1) religius, (2) jujur, (3) toleransi, (4) disiplin, (5) kerja keras, (6) kreatif, (7) mandiri, (8) demokratis, (9) rasa ingin tahu, (10) semangat kebangsaan, (11) cinta tanah air, (12) menghargai prestasi, (13) bersahabat atau komunikatif, (14) cinta damai, (15) gemar membaca, (16) peduli lingkungan, (17) peduli sosial, dan (18) tanggung jawab. Dari hasil pengamatan profil karakter siswa di SDN 05 Pagi di dapatkan hasil profil karakter siswa dari awal dan akhir pada gambar 3berikut.

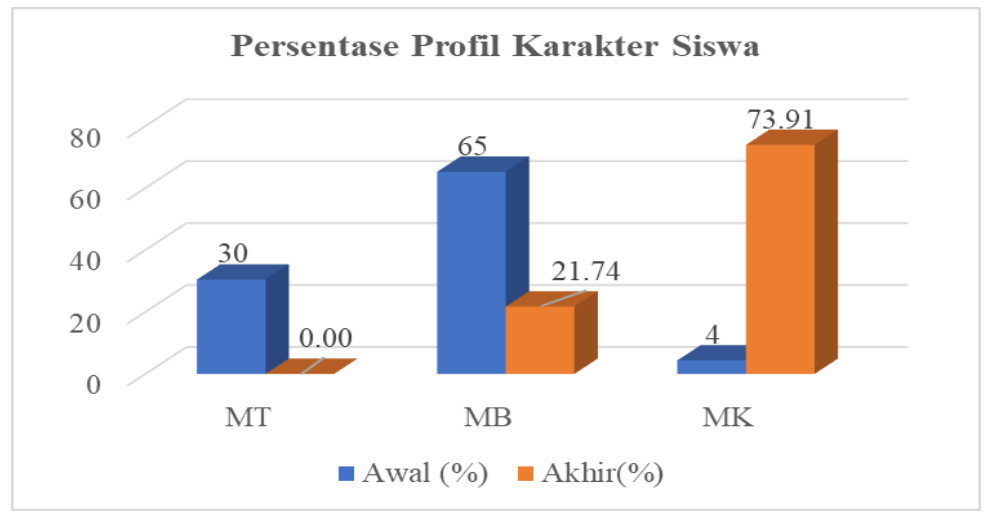

Gambar 3. Profil Karakter Siswa

Dari pengamatan dan hasil kuesioner dari yang sudah disebarkan ke siswa untuk mengetahui profil karakter siswa dapat dilihat, dari pengukuran awal dan akhir tedapat peningkatan. Pada kondisi awal butir karakter yang dalam kondisi mulai terlihat ada 30\% (kreatif, menghargai prestasi, religius, toleransi), sedangkan butir karakter mulai berkembang 65\% adalah rasa ingin tahu, peduli lingkungan, mandiri, cinta damai, kerja keras, menghargai, cinta tanah air, peduli sosial, demokratis, displin, jujur, gemar membaca dan tanggung jawab, dan $4 \%$ butir karakter yang membudaya adalah semangat kebangsaan. Pada tahap akhir pengamatan dan penyebaran kuesioner kepada siswa didapatkan hasil 21,74\% Mulai Berkembang (MB) yakni pada butir karakter religius, cinta tanah air, menghargai prestasi, disiplin, dan 73,91\% Membudaya (MK) yakni pada butir kreatif, peduli lingkungan, rasa ingin tahu, peduli sosial, jujur, mandiri, kerja keras, demokratis, toleransi, bersahabat, cinta damai, semangat kebangsaan dan gemar membaca. Perlu ditingkatkan secara menyeluruh karakter yang terus dikembangkan.

Hasil ini menunjukkan ada perkembangan walaupun tidak signifikan, karena terhalangnya situasi dan kondisi yang belum bisa mengamati secara langsung kegiatan PKM ini. Namun setidaknya hal ini perlu dilakukan secara konsisten agar penguatan Pendidikan karakter yang dicanamgkan pemerintah dapat terwujud. Karena penyelenggaraan penguatan Pendidikan karakter ini harus dilakukan secara berkelanjutan, melalui semua mata pelajaran, nilai tidak diajarkan tapai dikembangkan melalui proses belajar, dan proses pendidikan 
dilakukan secara aktif dan menyenangkan kepada siswa (Nadlir, 2016). Pendapat yang sejalan juga diungkapkan oleh (Fauzi et al., 2017), bahwa dalam penerapan pembelajaran menuju penguatan karakter siswa diperlukan pengajar yang kompeten, didukung oleh metode dan pendekatan yang efektif dan efisien sehingga dapat menumbuhkan penguatan karakter siswa. Karekter yang ditanamkan tentu saja harus bersumber dari dasar negara yang kita anut untuk diimplementasikan dalam kehidupan sehari-hari (Possamai \& Blasi, 2020); (Rachmadtullah et al., 2020).

Hal ini sejalan dengan penelitian (Wulandari \& Andhiarini, 2018), bahwa pemberdayaan guru dalam penguatan Pendidikan karakter penting dilakukan dengan sosialisasi, mengundang pemateri untuk memberikan pelatihan, kenudian diberikan pendampingan dalam berbagai kegiatan, dengan contoh-contoh penerapannya dalam kegidupan sehari-hari. Peneltian ini juga didukung oleh penelitan lainnya yang menyatakan bahwa sebelum melakukan pengajaaan yang bersentuhan dengan generasi penerus bangsa mesti diberikan kompetensi sosial dan kepribadian yang kuat agar meberikan suri tauladan bagi siswanya. Itulah bagian penting dari peran pendidik dalam pembentukan karakter siswanya (Megawati \& Kawatu, 2019); (Islam, 2017).

Pembiasaan dalam Pendidikan karakter juga harus selalu dilakukan, Karena pembentukan karakter bukalah sesuatu yang tiba-tiba terjadi, namun memerlukan proses yang Panjang dan terus menerus dan tahapan yang jelas. Pembisaan (habituation) dapat dilakukan bila adanya keteladanan (modelling), sehingga perlu adanya kerjasama yang baik dan secara terintegrasi dilakukan dalam pembelajaran di kelas dan dalam kehidupan sehari-hari (Rohman, 2016). Hal senada dikemukakan pula oleh (Dalyono \& Enny Dwi Lestariningsih, 2017) dalam penelitiannya bahwa untuk dapat terwujudnya peradapan bangsa haruslah memalui pendidikan budi pekerti yang tidak boleh terlepas dari lingkungan Pendidikan, baik dalam keluarga, sekolah, dan masyarakat. Hal ini dapat dilakukan dengan cara diintegrasikan nilai-nilai karakter dalam pembelajaran inti maupun tambahan dalam kegiatan-kegiatan pembelajaran. Sehingga akan dapat dilihat perkembangan secara menyeluruh penguatan karakter yang dialami oleh siswa.

\section{Conclusion}

Berdasarkan Dari hasil kegiatan Program Kemitraan Masyarakat dalam pemberdayaan kompetensi sosial dan kepribadian guru yang telah dilaksanakan dapat ditarik kesimpulan bahwa partisipasi aktif guru 55\% karena berbagai halangan yang terjadi di masa pandemic. Adanya peningkatan dalam penerapan profil kompetensi sosial sebesar $8 \%$ dan kepribadian sebesar 7\% dan Adanya peningkatan profil karakter siswa dari butir karakter yang diamati.

\section{References}

Dalyono, B., \& Enny Dwi Lestariningsih. (2017). Implementasi penguatan pendidikan karakter di sekolah. Bangun Rekaprima.

Fauzi, A. R., Zainuddin, Z., \& Atok, R. Al. (2017). Penguatan Karakter Rasa Ingin Tahu dan Peduli Sosial melalui Discovery Learning. Jurnal Teori Dan Praksis Pembelajaran IPS, 2(2), 79-88. https://doi.org/10.17977/um022v2i22017p079

Huda, M. N. (2018). Peran Kompetensi Sosial Guru dalam pendidikan. Ta'dibi : Jurnal Prodi Manajemen Pendidikan Islam, 2(September 2017), 227-249. https://ejurnal.stail.ac.id/index.php/tadibi/article/download/Peran Kompetensi Sosial Guru dalam pendidikan/3

Islam, S. (2017). Karakteristik Pendidikan Karakter; Menjawab Tantangan Multidimensional 
Melalui Implementasi Kurikulum 2013. Edureligia; Jurnal Pendidikan Agama Islam. https://doi.org/10.33650/edureligia.v1i2.50

Khusniati, M. (2012). Jurnal Pendidikan IPA Indonesia Pendidikan Karakter Melalui Pembelajaran Ipa. JPII. https://doi.org/10.15294/jpii.v1i1.2017

Komara, E. (2018). Penguatan Pendidikan Karakter dan Pembelajaran Abad 21. SIPATAHOENAN: South-East Asian Journal for Youth, Sports \& Health Education, 4(1), 17-26.

Marzuki. (2012). Pengintegrasian Pendidikan Karakter Dalam Pembelajaran Di Sekolah. Pengintegrasian Pendidikan Karakter Dalam Pembelajaran Di Sekolah, 1. https://doi.org/10.21831/jpk.v0i1.1450

Megawati, R., \& Kawatu, P. J. (2019). Kompentensi Sosial Dan Kompetensi Kepribadian Mahasiswa Ppl Program Studi Pendidikan Biologi Tahun Akademik 2018/2019. Jurnal Ilmiah Mandala Education, 5(2), 5. https://doi.org/10.36312/jime.v5i2.751

Nadlir, M. (2016). Perencanaan Pembelajaran Berbasis Karakter. Jurnal Pendidikan Agama Islam (Journal of Islamic Education Studies). https://doi.org/10.15642/pai.2013.1.2.338-352

Oviyanti, F. (2017). Urgensi Kecerdasan Interpersonal Bagi Guru. Tadrib: Jurnal Pendidikan Agama Islam, 3(1), 75. https://doi.org/10.19109/tadrib.v3i1.1384

Possamai, A., \& Blasi, A. J. (2020). Pancasila. In The SAGE Encyclopedia of the Sociology of Religion. https://doi.org/10.4135/9781529714401.n323

Prihartini, Y., Wahyudi, Hasnah, N., \& Ridha DS, M. (2019). Peran dan Tugas Guru dalam Melaksanakan 4 Fungsi Manajemen EMASLIM dalam Pembelajaran di Workshop. Jurnal Islamika: Jurnal Ilmu-Ilmu Keislaman, 19(02), 79-88. https://ejournal.iainkerinci.ac.id/index.php/islamika/article/download/327/323/

Putri, S. T., \& Syofyan, H. (2018). Pengaruh Kompetensi Guru Kelas Terhadap Minat Belajar Siswa Kelas IV pada Mata Pelajaran IPA di Sekolah Dasar Negeri Tanjung Duren Utara 02. Dinamika Sekolah Dasar.

Rachmadtullah, R., Syofyan, H., \& Rasmitadila. (2020). The Role of Civic Education Teachers in Implementing Multicultural Education in Elementary School Students. Universal Journal of Educational Research. https://doi.org/10.13189/ujer.2020.080225

Rohman, A. (2016). Pembiasaan Sebagai Basis Penanaman Nilai-Nilai Akhlak Remaja. Nadwa. https://doi.org/10.21580/nw.2012.6.1.462

Shah, N., \& Coles, J. A. (2020). Preparing Teachers to Notice Race in Classrooms: Contextualizing the Competencies of Preservice Teachers With Antiracist Inclinations. Journal of Teacher Education. https://doi.org/10.1177/0022487119900204

Sudrajat, A. (2011). Mengapa Pendidikan Karakter. Jurnal Pendidikan Karakter. https://doi.org/10.21831/jpk.v1i1.1316

Supadi, Dewi, W., Zulaikha, S., Nuphanudin, \& Soraya, E. (2020). Model Pengembangan Kompetensi Sosial dan Kepribadian Guru Berbasis Myers briggs type indicator/MBTI Berbasis Tekonologi informasi. International Journal of Psychosocial Rehabilitation, 24(3), 2077-2082. https://doi.org/10.37200/IJPR/V24I3/PR200954

Susanto, R., Syofyan, H., \& Rachmadtullah, R. (2020). Teacher Leadership in Class on The 
Formation of School Values and Characters of School-Ages. https://doi.org/10.4108/eai.11-12-2019.2290861

Syofyan, Harlinda; Rosyid, A. T. L. A. M. E. (2020). Application of Value Approaches in Science Learning for Elementary School Teacher Education Students. International Journal of Advanced Science and Technology, Volume 25(5), 8978-8981.

Syofyan.Harlinda. (2019). Kemampuan Dasar Mengajar Mahasiswa Pgsd Universitas Esa Unggul Pada Pembelajaran Ipa Di Sd. Seminar Nasional Ilmu Pendidikan Dan Multidisiplin, 88.

Winangun, I. M. A. (2020). Penguatan pendidikan karakter melalui literasi berbasis kearifan lokal. 4(2), 114-122.

Wulandari, F., \& Andhiarini, R. M. (2018). Pkm Pemberdayaan Guru Sekolah Dasar dalam Penguatan Pendidikan Karakter (PPK) Di Kecamatan Tulangan Sidoarjo. Jurnal ABDINUS : Jurnal Pengabdian Nusantara, 2(1), 40. https://doi.org/10.29407/ja.v2i1.11978

Zakaria, N. S., Zaini, A. R., Abdul Razak, A. Z., Azizan, M. R., Hamdan, H., Ismail, R., \& Ghazali, M. R. (2020). Kompetensi Guru Bahasa Arab Dalam Pengajaran Dan Pembelajaran Di Sekolah Rendah Kementerian Pendidikan Malaysia. The Sultan Alauddin Sulaiman Shah Journal (JSASS). 